\title{
T \\ A PRÁCTICA ONLINE DEL BUDISMO EN TIEMPOS DE PANDEMIA: RITUALES, COMUNIDAD Y MEDIATIZACIÓN
}

Catón Eduardo Carini Consejo Nacional de Investigaciones Científicas y Técnicas

La Plata - Argentina Orcid: http://orcid.org/0000-0003-3108-8183

\section{Introducción $^{1}$}

Las nuevas tecnologías de la información y la comunicación han transformado nuestra vida cotidiana de forma significativa, impactando en ámbitos tan variados como la economía, la educación, la política, la religión y las relaciones interpersonales. Hoy en día es posible comprar o vender casi cualquier cosa, pagar servicios, consultar las finanzas personales, hacer una carrera universitaria o encontrar pareja a través del ciberespacio. Las prácticas religiosas no han sido ajenas a estas mutaciones y se han visto afectadas en un grado tal que recién empezamos a comprender. La posibilidad que brinda el ciberespacio de sortear fronteras temporales, espaciales y culturales contribuye en gran medida al acercamiento a diversas tradiciones religiosas. Desde diversas plataformas y redes sociales, las personas pueden hallar nuevas experiencias no solo "en las iglesias de piedra, en los sacerdotes de carne y hueso, y en los rituales palpables, sino también en la religiosidad existente y disponible en los bits y píxeles en internet" (Sbardelotto 2014). Así, puede observarse una creciente tendencia

1 Agradezco la revisión y las sugerencias realizadas a este trabajo por la Mg. Asunción Iglesias y la Lic. Agustina Gracia. 
al desplazamiento de las prácticas religiosas al ciberespacio, de forma tal que los rituales pierden su anclaje en los contextos tradicionales debido al dislocamiento del espacio de los templos y a la creación de nuevos ambientes de culto en entornos virtuales descentralizados (Casey 2006; Kruger 2005; Radde-Antweiler 2006, 2008; Sbardelotto 2014).

El budismo se ha visto especialmente atravesado por las nuevas tecnologías de la información y la comunicación y ha sido pionero en consagrar internet como un espacio sacramental. A través de las pantallas de las computadoras personales y los teléfonos móviles es posible leer textos anteriormente inaccesibles, escuchar a maestros zen, lamas tibetanos y monjes theravada de cualquier parte del mundo y participar de comunidades transnacionales. Los practicantes budistas viven su religión no solo asistiendo a templos de piedra y madera, participando de rituales presenciales, o siguiendo a referentes de carne y hueso, sino también comprometiéndose con comunidades online y aprendiendo de maestros de todo el mundo. Al respecto, un creciente corpus de trabajos analiza la relación entre las nuevas tecnologías digitales y el budismo globalizado en el siglo XXI, dando cuenta especialmente del proceso de negociación entre el mundo online y el offline por el cual se crean nuevas prácticas rituales y se desarrollan nuevas formas de comunidades virtuales ${ }^{2}$ (Campbell 2005; Campbell \& Connelly 2012; Carini 2019a; Carini \& Gracia 2016; Connelly 2010; Gracia 2019; Grieve 2010; MacWilliams 2006; Radde-Antweiler 2008; Soper 2014; Tarocco 2017; Yonnetti 2017).

Debido a la pandemia del Covid-19 muchos países del globo han cerrado sus fronteras y decretado la cuarentena o aislamiento social preventivo, trastocando la vida cotidiana de la comunidad internacional de una forma nunca antes vista. De una forma drástica, la crisis sanitaria provocada por el coronavirus ha dado un rápido impulso a la tendencia al desplazamiento del budismo al ambiente digital que se viene observando desde hace algunos años. Se incrementó el empleo de tecnologías innovadoras y se abrió el juego a transformaciones profundas en el ámbito del ritual, la meditación y la transmisión de la enseñanza. En estos días de pandemia y cuarentena, el budismo es conocido, aprendido y practicado a través de flujos comunicacionales que circulan por redes digitales. En este trabajo indagamos las mudanzas en el empleo de internet en el marco de grupos budistas de la Argentina debido al aislamiento social preventivo y obligatorio decretado en el territorio de este país en marzo del

2 Como señala Bitarello (2008), la dimensión virtual no es nueva, ni se limitan al ambiente digital: los mundos virtuales se encuentran presentes desde hace milenios en el ámbito de la religión, la literatura y el arte. Todos comparten la experiencia de la inmersión en una realidad alternativa no material, a la cual se accede por medio de algún dispositivo, ya sea una computadora, un sueño, un libro o un ejercicio de visualización. Además, se accede a ellos de forma incorporada (embodied) y se realizan acciones ordinarias como sentarse, caminar, comer, pelear y coquetear. Sin embargo, el mundo virtual posibilitado mediante la tecnología digital presenta algunos rasgos que lo diferencian del mundo virtual creado mediante las narrativas míticas, la lectura de una novela, o la contemplación de un film, entre los cuales destaca la posibilidad de establecer una relación de interactividad. Teniendo en cuenta esta amplitud semántica del término "virtual", cuando en este trabajo lo empleamos nos referimos específicamente al espacio social creado por medio de las nuevas tecnologías digitales e internet. 
año 2020. Específicamente, exploramos el proceso de creación de nuevos rituales online y el traslado a formato digital de prácticas previamente realizadas de manera offline, haciendo hincapié en cuestiones como la accesibilidad, la interactividad y la sociabilidad. Asimismo, se pondrá especial atención a la forma en que se construye un sentimiento de comunidad que atraviesa las fronteras locales, nacionales y globales.

Para dar cuenta de este fenómeno nos apoyaremos en algunos aportes teóricos referidos a la problemática de la identidad, la transnacionalización y la globalización (Anderson 1983; Appadurai 2001, 2005; Portes, 2003; Robertson, 1994; Strauss 2000; Vertovec 2003). Específicamente, retomamos la advertencia metodológica señalada por Robertson (1994), que consiste en apartarse de la perspectiva que toma a la sociedad nacional como unidad de análisis. Partimos del supuesto que indica que abordar los aspectos transnacionales de los grupos religiosos -entendiendo como "transnacional" aquello que "refiere a los múltiples lazos e interacciones que unen a personas e instituciones a través de las fronteras de los Estados-Nación" (Vertovec 2003:353) - es clave para comprender los procesos sociales de consolidación de los mismos. En este punto es pertinente recuperar la definición de actividades transnacionales propuesta por Alejandro Portes (2003), quien las concibe como aquellas que se realizan en forma habitual a través de las fronteras nacionales y que requieren de un compromiso de tiempo significativo por parte de sus participantes. Dentro de esta perspectiva, el autor enfatiza la necesidad de mirar no solo a los actores poderosos sino al conjunto de actores sociales.

Además, siguiendo a Appadurai (2001), entendemos que los flujos culturales globales ocurren en la actualidad a través de crecientes dislocaciones entre cinco dimensiones o "paisajes": los paisajes étnicos, los mediáticos, los tecnológicos, los financieros y los paisajes ideológicos. Estos paisajes son los bloques con los que se construye lo que este autor, extendiendo la idea de Anderson (1983), denomina como "mundos imaginados", es decir, "los múltiples mundos que son productos de la imaginación históricamente situada de personas y grupos dispersos por todo el globo" (Appadurai 2001:44). Así, el mundo actual se caracteriza por el rol que juega la imaginación en la construcción de aspiraciones colectivas, ahora mediadas por las tecnologías de comunicación modernas. En este contexto, se puede observar una erosión en la relación entre los vecindarios espaciales y los virtuales, y una dislocación entre los movimientos colectivos, el territorio y la subjetividad. En efecto, las nuevas tecnologías digitales generan vecindarios virtuales no limitados a determinado territorio, posibilitando la construcción de comunidades de imaginación y comunidades de intereses entre personas geográficamente distantes (Appadurai 2001).

Agregamos aquí que los grupos budistas estudiados pueden pensarse como "comunidades de práctica", en el sentido que le otorga Strauss (2000) a esta expresión, es decir, entendiendo las prácticas como medios de construir relaciones sociales que cruzan culturas y naciones. Las prácticas son "modos de estar en el mundo" que proveen las bases de estas comunidades. En este sentido, el elemento 
central en la articulación de la identidad colectiva no es la adhesión a un conjunto de creencias, sino la identificación con determinadas "tecnologías el yo"3 que requieren una práctica corporal específica, como el yoga o la meditación.

El referente empírico de este trabajo está integrado por tres grupos argentinos que se inscriben dentro de las tres ramas principales del budismo: mahayana, theravada y vajrayana ${ }^{4}$. El primero está representado a través de la Asociación Zen de América Latina, perteneciente a la sangh $a^{5}$ del maestro Stéphane Kosen Thibaut, continuador de la tradición del zen enseñada en Europa por el maestro japonés Taisen Deshimaru ${ }^{6}$. El grupo theravada es la sede argentina de la organización internacional Meditación Vipassana, fundada por el maestro birmano S. N. Goenka? . El grupo vajrayana estudiado es Tashigar Sur, perteneciente a la Comunidad Dzogchen Internacional, fundada por el maestro tibetano Namkhai $\mathrm{Norbu}^{8}$. Cabe mencionar que los tres grupos representan un budismo occidental laico, modernista -o postmoderno, como sugiere Baumann $(2001,2002)$ - que pone el acento en la meditación y en otras tecnologías del yo, como el yoga y la danza tibetana. La membrecía está integrada por argentinos sin antepasados orientales, que no viven en un templo y que combinan su práctica del budismo con una vida familiar, social y laboral integrada a la sociedad ${ }^{9}$. En las tres organizaciones hemos realizado un trabajo de campo etnográfico presencial de larga data sobre sus dinámicas sociales, prácticas rituales y cosmovisión. A partir de esta investigación, la metodología empleada para lograr los objetivos propuestos aquí pone acento en una etnografía digital, ocupada en indagar el proceso de mediatización generado por la crisis sanitaria del Covid-19 y en analizar comparativamente las similitudes y diferencias que se pueden observar en los tres casos estudiados.

\section{Nuevos rituales online}

\section{Tras el "aislamiento social preventivo y obligatorio" decretado en Argentina el}

3 Entendidas como aquellas prácticas que posibilitan al sujeto realizar ciertas "operaciones sobre su cuerpo y su alma, pensamientos, conducta, o cualquier forma de ser, obteniendo así una transformación de sí mismos con el fin de alcanzar cierto estado de felicidad, pureza, sabiduría o inmortalidad" (Foucault 1990:48).

4 Los datos analizados sobre las trasformaciones en el uso de internet debido a la pandemia abarcan desde marzo hasta agosto de 2020. Posteriormente, se clausuró la búsqueda de nueva información y se procedió a elaborar el presente escrito. De todas maneras, tenemos conocimiento de que, aunque pudo haber cambios menores en la forma de organización y contenidos de las actividades virtuales descriptas en las páginas siguientes, la situación actual es prácticamente la mism

5 "Sangha" (sánsc.) es un término que designa a una comunidad de practicantes que siguen a un maestro.

6 Sobre la cosmovisión, los rituales, la identidad, la historia y otros rasgos socioculturales de este grupo, se sugiere revisar Carini (2012).

7 Sobre la historia y los principales rasgos cosmológicos y sociológicos de esta organización budista, ver: Carini (2017).

8 Sobre el origen y las principales características socioculturales de la Comunidad Dzogchen Internacional, ver: Carini (2019b).

9 Si bien el grupo zen tiene ordenaciones monásticas ritualmente marcadas por el uso de ropas tradicionales durante la meditación y el afeitado opcional de la cabeza, la persona ordenada como monje o monja no vive en un templo y puede tener pareja, familia y trabajo en el mundo social más amplio. Sobre el sentido de la ceremonia de la ordenación en el marco de la Asociación Zen de América Latina, ver: Carini (2009) 
20 de marzo de 2020, los centros budistas de la Asociación Vipassana de Argentina, la Asociación Zen de América Latina y Tashigar Sur cerraron sus puertas. Para el caso de Vipassana, la Comisión Directiva de la Asociación propuso practicar todos los días meditación en casa y de forma online. Luego de realizar una encuesta anónima para determinar los momentos del día preferidos para llevar adelante la práctica, organizaron "Meditaciones en grupo" a las 8.00 y las $19.00 \mathrm{hs}$. Esta modalidad implicó sumarse a un grupo de WhatsApp y luego recibir dos veces por día un mensaje con el recordatorio de la actividad y un link a los audios que guían la meditación, grabados previamente por el principal referente del grupo, Goenka. En abril, se organizaron sesiones de meditación más extensas por Zoom los martes de 18.00 a $21.00 \mathrm{hs}$. y los sábados de 9.00 a $12.15 \mathrm{hs}$., con un profesor ${ }^{10}$ contestando preguntas los últimos minutos. Finalmente, en mayo se incorporaron "meditaciones grupales" diarias por Zoom a las 7.00 y a las 20.00 hs., y "jornadas de meditación online" todos los domingos de 7.00 a 12.15 hs. Más allá de las diferencias de horario, la modalidad de meditación por Zoom no difiere de la que se realiza a través de WhatsApp, pues propone entrar a la aplicación de teleconferencias con el sólo fin de escuchar los audios con las instrucciones, sin activar la cámara o el micrófono.

Por otra parte, en el marco de la comunidad que sigue al maestro zen Stéphane Kosen Thibaut, las modalidades de participación online registradas durante el aislamiento social obligatorio del año 2020 se basaron en una serie de experiencias que tuvieron lugar durante el año anterior. Ya en mayo de 2019 se había inaugurado una página de Facebook llamada "Dojo ${ }^{11}$ Virtual Kosen Sangha" y organizado la "primer jornada histórica" de meditación realizada por Zoom, conectando los "dos hemisferios del mundo" mediante un "ZaZoom con nosotros en todo el planeta", haciendo un juego de palabras entre "zazen"12 y "Zoom". La transmisión del evento online se realizó desde el dojo de Suecia, dirigido por la maestra zen Paula Reikuku Femenias. En los dos meses siguientes se realizaron sendas jornadas de "ZaZoom", presentadas como un "espacio para practicantes sin dojo físico" que posibilita practicar "zazen en todo el mundo".

El éxito de estas primeras experiencias llevó a que, en agosto de 2019, se realice el primer zazen online dirigido por el maestro Kosen durante el Campo de Verano ${ }^{13}$ de 2019 desde el templo Yujo Nyusanji de Francia. Con el objetivo de prever posibles dificultades técnicas derivadas de la cantidad de personas conectadas, se realizó un ensayo previo y se dispuso que los participantes no fueran personas individuales sino dojos locales. La jornada sumó unos veinte grupos de práctica de Latinoamérica. Ya probada y aceptada, la nueva modalidad de meditación online quedó establecida en el espectro de actividades de la sangha como un complemento, un "espacio virtual

10 Término nativo que designa a alguien autorizado por Goenka u otro profesor antiguo para enseñar meditación vipassana.

11 "Dojo" (jap.) hace referencia al lugar de práctica de la meditación zen.

12 "Zazen" (jap.) designa a la práctica de la meditación zen que se realiza sentado con las piernas cruzadas.

13 El Campo de Verano es un evento que dura de uno a tres meses, donde se reúnen los practicantes para practicar meditación zen de forma intensiva. 
habilitado para practicantes sin dojo en su ciudad o por razones de itinerancia", como rezaba la publicación en Facebook que convoca al evento. En el mes de septiembre de 2019, se dispuso un encuentro semanal de "ZaZoom online" para los centros de Latinoamérica y otro para los situados en Europa. Al mismo tiempo, se creó un sitio web "zazenathome.org" con el cronograma de actividades e información para quienes tuvieran interés en participar.

Ya iniciada la cuarentena, la práctica online dejó de pensarse como un complemento de la meditación presencial y pasó a ser la protagonista, pues aumentó notoriamente la cantidad y el tipo de eventos trasmitidos digitalmente. Específicamente, se publicó un cronograma con nuevos horarios (dos veces al día, a la mañana y a la noche) para "cubrir la suspensión temporal de zazenes en los dojos físicos". La propuesta de trasladar la práctica diaria al espacio virtual fue fomentada con explicaciones como la que figura en la mencionada página web zazenathome.org: "El hecho de practicar en grupo permite conservar la regularidad de la práctica, y además al saber que un maestro Zen está observando tu postura, te motiva a corregirla y a sentarte correctamente. El zazen de la mañana es el que influencia tu día entero, es el zazen del practicante sincero". Otros maestros de la sangha tales como Pierre Soko Lerouz, Toshiro Taigen Yamahuchi y Ariadna Dosei Labbate comenzaron a transmitir ocasionalmente prácticas de meditación online. Además, se sumaron otras actividades previamente realizadas de manera presencial tales como las jornadas de "costura de kesa"14, las clases de yoga "para ayudar a la postura, fortalecer el sistema inmunitario y dinamizar el cuerpo en reclusión por la cuarentena", y las jornadas de "Shiat-Zoom", es decir, de masaje japonés vía Zoom. Los eventos realizados por esta plataforma se empezaron a retransmitir en vivo por Facebook y de esta forma quedaron registrados.

Continuando con el relevamiento del proceso de mediatización impulsado por la pandemia, el centro argentino Tashigar Sur creó, al inicio de la cuarentena, la página de Facebook "Grupo de Práctica Tashigar Sur 2020" para todos los miembros de la comunidad. Bajo la consigna "Tashigar Sur llega hasta tu casa, estés donde estés, para que puedas acceder a una pequeña parte de las maravillosas enseñanzas que son el legado de nuestro Maestro", el grupo virtual sumó más de ochocientos miembros, los cuales se abocaron a la tarea de coordinar y participar de las prácticas y las enseñanzas dzogchen ${ }^{15}$ de forma online. Como ensayo, el domingo 15 de marzo de 2020 se realizó la primera práctica online, que consistió en un rito de invocación a Tara Verde, una divinidad budista femenina considerada como especialmente eficaz para superar obstáculos. Casi una semana después, y al día siguiente del inicio de la cuarentena en Argentina, es decir, el 21 de marzo, comenzaron las actividades regulares. En pocos días se estableció un programa diario que incluyó yantra yoga, danza del vajra ${ }^{16}$, prácticas meditativas

14 Se refiere a la confección ritual de la túnica de los monjes zen según una técnica tradicional (Carini 2009).

15 Esta es una tradición dentro del budismo tibetano, asociada generalmente a la escuela nyingma.

16 Sobre la performance y el simbolismo del yoga y la danza tibetana realizada en el marco de la Comunidad Dzogchen Internacional, ver: Carini (2016). 
tántricas que incluyen visualizaciones y recitado de mantras, y clases de "respiración armónica". Varias semanas después fue tomando impulso otra clase de actividad, la integrada por charlas y conferencias dictadas por instructores y practicantes. Para agosto de 2020 se habían realizado más de cuarenta, las cuales versaron sobre temas tan variados como "Pautas para el manejo del calendario tibetano", "La Psicoterapia y los tres modos de trabajar con las emociones negativas en el budismo", "Resistencia, relajación y liberación", "La importancia de descubrir y entrenar la respiración correcta para la vida cotidiana" y "Budismo y derechos humanos".

Cabe mencionar que, a las actividades referidas previamente, se sumaron nuevas propuestas de índole recreativas, brindadas por diferentes miembros de la comunidad desde sus países de origen. Entre ellas, se destacan los talleres de ikebana ${ }^{17}$, las clases de cocina tibetana, italiana y argentina, así como propuestas de películas afines al budismo, tales como documentales del Dalai Lama. Si bien en un primer momento las trasmisiones no quedaban registradas, pasado un tiempo estas prácticas comenzaron a grabarse y de este modo se abrió la posibilidad de que los practicantes interesados pudieran acceder a ellas. Al uso de Facebook se incorporó, durante el mes de mayo, el de la plataforma Zoom, el cual fue desplazando paulatinamente a Facebook Live. Desde el inicio, el apretado conjunto de actividades cotidianas se anunció mediante un cronograma diario y otro semanal. Las grabaciones de todas las actividades realizadas se pueden solicitar por e-mail a la secretaría de Tashigar y se comparten por Google Drive. Luego de cuatro meses de cuarentena, y otros tantos de práctica online, los integrantes del grupo tuvieron a su disposición casi quinientos encuentros por Zoom o Facebook Live brindados por unos treinta instructores y cerca de cincuenta practicantes avanzados de diecisiete países diferentes.

\section{Accesibilidad, interactividad y globalización}

El proceso de mediatización por el cual se volcaron al ambiente digital una multiplicidad de prácticas rituales y sociales presenta algunos rasgos que atraviesan los tres grupos budistas estudiados. En primer lugar, es preciso mencionar que sus líderes han tenido una actitud respetuosa hacia las medidas de aislamiento decretadas por el gobierno y no se observan resistencias o desafíos a las normas establecidas por las autoridades sanitarias para superar la pandemia. Al mismo tiempo, comparten una mirada crítica con respecto a los medios de comunicación periodísticos debido al estado de miedo y pánico moral que eventualmente podrían suscitar. Por ejemplo, un profesor de vipassana señaló al respecto que:

17 Arte japonés del arreglo floral. La convocatoria publicada en Facebook rezaba: "Ikebana, el camino de las flores. Como todas las cosas que hacemos, son un reflejo de nuestro interior. Del diálogo con las flores surgen manifestaciones de nuestro ser y como una meditación o un mudra nos pueden ayudar a reconocer aspectos que no teníamos muy presentes". 
Los medios nos inundan con rumores alarmantes. En todo momento, el miedo obsesivo a una amenaza inminente para la vida, proveniente del exterior o del interior, nubla nuestra visión, impide la comprensión correcta y nos lleva a tomar decisiones equivocadas e, incluso, nos paraliza al punto de no saber cómo protegernos. Esto se convierte en un disparador de nuestros propios miedos e inseguridades internas.

(Vipassana Argentina - Estudiantes Antiguos (Oficial), Facebook, 2020)

En la misma línea, el maestro zen argentino Toshiro Taigen Yamauchi expresaba durante una meditación online:

Ayer me escribió un señor a quien aprecio, que siempre me escribe, muy simpático, se cree todas las teorías conspirativas (...) Y me decía: "mire los signos, hay plagas en el mundo, está la peste, explotan los volcanes, hay peligro de que haya cuatro huracanes simultáneos. Maestro, iesto es el comienzo del fin? ies el comienzo del apocalipsis? ¿qué va a pasar?". Y yo comprendí inmediatamente su miedo, su terror, porque todo está armado para que tengamos terror; basta con ver un noticiero (...). Y uno comprende el terror de la gente. Pero yo le contesté que en el Zen no nos preocupamos por lo que va a pasar. No nos preocupamos por lo que va a pasar mañana. En el Zen simplemente nos ocupamos del aquí y ahora.

(Dojo Zen Virtual Kosen Sangha, Facebook, 2020)

Otro de los rasgos que comparte el proceso de mediatización referido en el apartado anterior es que se llevó a cabo teniendo como base algunas experiencias previas con las tecnologías digitales e internet. En el caso de vipassana, los audios grabados por el maestro Goenka para guiar la meditación ya se encontraban disponibles de forma online para quienes quisieran practicar en su casa. En el caso del zen, se empezó a experimentar con un "Dojo Virtual" un año antes de la pandemia. Por su parte, la Comunidad Dzogchen Internacional cuenta con una larga trayectoria de usos de medios de comunicación digital, especialmente el sistema webcast mediante el cual se reúnen virtualmente los miembros del grupo dispersos por todo el mundo (Carini 2019a). Con todo, hay que destacar que estas herramientas preexistentes se llevaron hasta las últimas consecuencias durante la crisis sanitaria y la cuarentena. No sólo se aceptaron los medios de comunicación digitales como una tecnología apropiada para la práctica, sino que se alentó activamente a los miembros a que se sumaran a las actividades online. En otras palabras, el proceso de mediatización fue fomentado y conducido de manera reflexiva por parte de los responsables de los grupos relevados a través de acciones de difusión concretas. Por ejemplo, en el caso del zen se realizaron dos videos institucionales mostrando las bondades de compartir 
la práctica con los demás por medio de Zoom. Además, en el mencionado sitio web "zazenathome.org" se ofrecieron explicaciones sobre su uso.

Como en el caso del zen, en Tashigar Sur se realizó una labor mancomunada destinada a promover el acercamiento de la membrecía a las nuevas tecnologías digitales mediante la labor pedagógica -y apologética- de las voces autorizadas de la comunidad, es decir, de los instructores y profesores acreditados para conducir las actividades del grupo. Entre estas acciones, se destacan la elaboración y publicación de instructivos para acceder a la página del grupo en Facebook, realizar búsquedas en la sección "conversación", y explicaciones respecto de herramientas como el "vivo" y sus formas de interacción. Además, se brindó una charla online dedicada a explicar el uso del Zoom. En otra conferencia titulada "Distancia Social y Comunicación" se trató el tema de la pandemia, los medios de comunicación y las redes sociales. Allí, el disertante destacó la importancia de aprovechar el aislamiento sanitario que provocó la pandemia del Covid-19 para la práctica espiritual. Refiriéndose a la pertinencia de internet para mediatizar esta práctica, enfatizó que a través de las nuevas tecnologías se puede hacer prácticamente todo lo que se hace de forma presencial.

En otro orden de cosas, vale destacar que el fenómeno de mediatización está atravesado por un conjunto de mecanismos de restricción característico de cada grupo, configurando diferentes grados y modalidades de accesibilidad. En general, las actividades online reproducen los límites que identifican simbólicamente la pertenencia a la comunidad offline. En el grupo de vipassana, la frontera más relevante es la que demarca a los "estudiantes antiguos" de los demás. Este término se refiere a las personas que han completado al menos un curso presencial de diez días de meditación en uno de los centros de la organización ${ }^{18}$. Para participar en las meditaciones por WhatsApp o Zoom se requiere haber terminado un curso de diez días. A partir de ese momento, el estudiante tiene acceso a los audios para practicar en su casa, al material de lectura y a las páginas de Facebook que agrupan a los miembros. Por ello, al inicio de la cuarentena se enfatizó el pedido de "mantener este WhatsApp sólo entre meditadores antiguos de esta tradición". En el caso de Tashigar Sur, la frontera ritual y simbólica más importante que delimita a los insiders de la comunidad es la experiencia de haber recibido la "transmisión" por parte del maestro Namkhai Norbu. Es un rito iniciático durante el cual el maestro "transmite"

18 En estos cursos la práctica de meditación sigue un horario riguroso que comienza a las cuatro de la madrugada y finaliza a las nueve y media de la noche. Durante el día, la jornada se estructura sobre un ajustado cronograma que se basa en diez u once horas de meditación, con intervalos para la alimentación y el descanso. Existe una completa segregación del mundo exterior y no está permitido hablar entre los participantes o el uso del teléfono móvil. Tampoco la lectura, la escritura y la música, con el fin explícito de dedicar toda la atención y esfuerzo a aprender y practicar la técnica de vipassana. Existe un estricto "código de disciplina" que incluye cinco preceptos: la abstención de matar cualquier ser vivo (incluyendo insectos tales como hormigas y mosquitos), de robar, mentir, de cualquier tipo de actividad sexual y del consumo de intoxicantes (incluidos el alcohol, el tabaco, las pastillas para dormir, etc.) Finalmente, existe una completa segregación de los sexos, con dormitorios, sanitarios, duchas, comedor y espacios de esparcimiento separados. Además, la comida es vegetariana y no es posible llevar alimentos al centro (Carini 2017). 
al aspirante una "visión de la naturaleza búdica", un estado de iluminación o de gracia espiritual mediante el otorgamiento de una suerte de experiencia numinosa que revela al discípulo el bien de salvación budista -denominado también "estado de presencia" o "rigpa"- al comienzo de su camino espiritual, experiencia que luego debe cultivar y afianzar a través de años de práctica. A partir de ese momento, es considerado un "hermano vajra" es decir, alguien unido al resto de la comunidad por lazos sagrados y miembro del linaje espiritual del maestro. La transmisión no solo genera un vínculo espiritual indeleble con este último, sino también con el resto de sus discípulos, construyendo una frontera simbólica que delimita un "nosotros" de un "otro". Haber recibido la transmisión es el requisito fundamental para participar en la vida online y offline de la comunidad (Carini 2019a). Ese mismo criterio se sostuvo para la admisión dentro del grupo de Facebook organizado al momento de mediatizar las prácticas durante la cuarentena, y se solicitó enfáticamente a sus integrantes no compartir los links de las charlas y las enseñanzas con personas que no hayan recibido la transmisión.

En el caso del zen, si bien las distinciones rituales y simbólicas que identifican a los que pertenecen al grupo son muchas -la ordenación, las vestimentas, el cabello afeitado, etc.- no restringen la accesibilidad de los nuevos practicantes. Como en el mundo offline, donde cualquier persona puede dirigirse a un dojo y practicar meditación zen, en el espacio virtual todos los interesados pueden participar del grupo de Facebook. El único requisito es haber recibido una "introducción al zazen" en la cual se enseña la manera de sentarse correctamente, la forma de respirar y la actitud del espíritu que es preciso cultivar. Para superar esta barrera, al poco tiempo de la cuarentena se organizaron introducciones al zazen en el Dojo Virtual para las personas que se acercaban por primera vez a la práctica, brindadas los días sábados por monjes de la comunidad.

Hay que mencionar aquí que, en el caso del budismo tibetano y el vipassana, también podemos identificar algunos mecanismos que tienen por objeto superar las barreras que las normativas pre-pandémicas establecen, aunque sólo permiten un acceso parcial a quienes no hayan recibido la "transmisión" dzogchen o no sean "estudiantes antiguos" de vipassana. Por ejemplo, transcurridos dos meses de cuarentena se ofrecieron "sesiones de anapana" 19 todos los domingos, destinadas a quienes nunca han participado de un curso de meditación presencial de vipassana pero quieren acercarse a esta práctica mediante un breve ejercicio preliminar. Así, los meditadores antiguos "pueden asistir con familiares, amigos y todos quienes deseen aprender a meditar". De manera similar, en Tashigar Sur, algunas de las charlas y prácticas de yoga fueron abiertas a todo público y se indicó en el sitio de Facebook que se podían compartir con parientes, amigos y allegados que no hayan recibido la transmisión.

19 Anapanasati, o meditación en la cual se centra la atención en la respiración. 
Otro aspecto central de la mediatización del budismo que incrementa la accesibilidad es el económico, pues se ofrecen experiencias y actividades que antes de la crisis sanitaria global debían ser obligatoriamente abonadas. Existe un flujo de dinero desde los participantes hacia los organizadores de las prácticas online, pero es de carácter opcional. Esta voluntarización de la economía virtual es visible en los momentos en que se apela a la buena voluntad de los miembros para que dejen su contribución. Por ejemplo, en el caso del zen, se señaló en ocasión de una jornada intensiva de práctica de meditación que "será para apoyar el Dojo Zen de Mar del Plata en el sostenimiento del espacio de práctica presencial (...). No se ha establecido arancel para la jornada, propiciando la colaboración a través de la práctica de fusé -don, entrega- de corazón a corazón”"20. De forma comparable, en Tashigar Sur periódicamente se publicó el siguiente mensaje:

Tal vez no todos sepan que todas las prácticas, charlas y enseñanzas que estamos compartiendo son guiadas o impartidas generosamente por instructores y practicantes más antiguos, a quienes estamos infinitamente agradecidos. Esto nació como una forma de estar conectados a pesar de la pandemia, y se ha transformado en una hermosa manera de compartir, estar juntos, y sentir que somos realmente una enorme familia sin importar el lugar del mundo en el que estemos. Quienes como parte de esa familia quieran y puedan contribuir al sostenimiento de las instalaciones y actividades de Tashigar Sur (...) son invitados a efectuar sus donaciones.

(“Grupo de práctica Tashigar Sur 2020”, Facebook).

En el caso de la organización Vipassana, cabe advertir que este tipo de economía voluntaria es un rasgo previo a la pandemia, ya que los cursos de diez días son gratuitos y se sostienen con el aporte voluntario de los "estudiantes antiguos". Así, solamente se puede donar dinero si previamente se ha completado al menos un curso de diez días de meditación (Carini 2017). No obstante, pueden notarse algunos fenómenos que apuntan en el mismo sentido que los otros casos estudiados pues, por ejemplo, la editorial Pariyatti, una organización estrechamente relacionada que ofrece libros, material audiovisual, accesorios de meditación, peregrinaciones y cursos de lengua pali, puso a disposición de los "estudiantes antiguos" algunos recursos online de forma gratuita al inicio de la pandemia.

Otro aspecto de la práctica online que sigue la lógica presencial es el de la interactividad. Diversos autores han destacado que las prácticas religiosas online ofrecen la posibilidad de establecer este tipo de relaciones debido a la naturaleza audiovisual y sincrónica del medio digital (Bitarello 2008; Grieve 2010). Sin embargo, y siguiendo la advertencia de Helland (2005), existen diversos grados de

20 Sobre la noción de fusé y su relación con la economía del don en el marco de este grupo zen, ver: Carini (2010). 
interactividad, que puede ir desde el bajo nivel implicado en acciones tales como solicitar una plegaria o subscribirse a un newsletter, hasta dinámicas altamente interactivas donde es posible relacionarse con los demás participantes con libertad. De las tres organizaciones aquí relevadas, la Asociación Vipassana es la que presenta el menor grado de interactividad de los tres casos, en continuidad con la lógica que muestra en las prácticas offline. En los cursos presenciales de diez días de duración no se puede hablar ni interactuar a través de gestos o miradas con los demás participantes, y solamente es posible conversar con el instructor o la instructora encargada de dirigir el curso durante cinco minutos al día para resolver dudas relacionadas con la técnica. En la práctica online se reproduce esta limitación de la interactividad pues, como mencionamos arriba, el grupo de WhatsApp solamente envía el recordatorio a la hora de meditar y el audio con las instrucciones, pero no se puede interactuar a través de él con los demás participantes. Esta regla a menudo es enunciada explícitamente con el siguiente mensaje: "(el grupo de WhatsApp) no debe ser utilizado para intercambios de mensajes. Además, una vez superada esta crisis sanitaria este grupo será disuelto y regresaremos a las meditaciones en grupo oficiales de manera normal".

Las meditaciones por Zoom no agregan muchas más posibilidades de interacción pues, como referimos, la cámara y el micrófono de todos los participantes se encuentran desactivados y solamente se escucha el audio con la instrucción grabada por Goenka. En las ocasiones en las cuales un profesor responde preguntas los días sábados al finalizar el período de práctica de tres horas de duración, este puede ser visto y escuchado por todos los participantes, aunque ellos continúan con sus cámaras y micrófonos apagados, y no pueden verse ni comunicarse entre sí. Las preguntas se escriben en el chat de Zoom y son leídas solamente por un moderador que las comunica al profesor y al resto de los presentes. Incluso en el grupo de Facebook que reúne todos los estudiantes antiguos de Argentina, donde se anuncian las novedades y se comparten textos inspiradores, fotos de los centros y otro tipo de información general, los comentarios se encuentran en la mayor parte de los casos "desactivados", limitando la posibilidad de interacción a cliquear en el ícono de "me gusta"21.

En el caso de la sangha del maestro Kosen, el grado de interactividad por los canales digitales oficiales es mucho mayor. Cada participante trasmite su imagen por Zoom durante la meditación de acuerdo a ciertas pautas comunes. En este sentido, se realizó un video con "recomendaciones de cómo poner la cámara para el zazen

21 Sin embargo, cabe mencionar que se pudo constatar un incremento en otras modalidades informales de práctica diaria vía WhatsApp, como por ejemplo la creación de grupos "no oficiales" que tienen por objeto compartir esta práctica. En mi experiencia de campo, si bien conocía la existencia de este tipo de grupos, no fue sino hasta el inicio de la pandemia que me agregaron a uno de ellos. Aquí la modalidad también implica compartir el audio para meditar, aunque los horarios sean variables. Cuando un miembro del grupo se va sentar, anuncia su intención (y quizás el tiempo que planea meditar) para invitar a otros a que se unan. Si alguien lo hace, lo anuncia. Ocasionalmente, se agradece por compartir la práctica y se realizan otros intercambios informales tales como muestras de afecto y de aliento a través de emoticones y deseos de buenas noches. Probablemente, estos grupos de WhatsApp informales que permiten la interacción son un soporte importante de la practica comunitaria en el caso de los practicantes de vipassana, aunque sean más difíciles de rastrear y cuantificar por su carácter no oficial. 
online" indicando el ángulo, la distancia y la iluminación apropiada. La justificación explicitada sobre el sentido de estas indicaciones es que facilitan a quien dirige la meditación la posibilidad de "observar las posturas y corregirlas como en el dojo físico". Además, la práctica online desde cada hogar procura emular lo más posible el mundo offline, pues se mantienen las marcas simbólicas y las prácticas rituales que identifican a la comunidad. De manera que los practicantes -especialmente los que se han ordenado como monjes- exhiben sus cabezas afeitadas y se atavían con los atuendos tradicionales zen tales como kolomos, kimonos y kesas (Carini 2009), y desarrollan la ceremonia completa que inaugura o cierra cada período de zazen, la cual incluye el recitado de textos sagrados y las prosternaciones. Asimismo, y como en la modalidad presencial, las prácticas online no solo abarcan la meditación zen y las ceremonias y rituales asociados, sino que registran los momentos de socialización informal posteriores, donde, por ejemplo, el maestro Kosen saluda a los participantes, ríe e intercambia bromas con ellos.

De todas formas, es en Tashigar Sur donde se observa el más alto grado de interactividad. Allí es posible intercambiar mensajes y opiniones en los grupos de WhatsApp, Facebook y Zoom. En la charla "Distancia Social y Comunicación" mencionada previamente, se hicieron recomendaciones sobre las trasmisiones en vivo, cubriendo aspectos tales como la forma de mirar la cámara para generar la sensación de estar hablándole a alguien y el adecuado uso de la luz para iluminar a quien transmite, los diferentes tipos de micrófono y cómo usarlos, y la importancia del uso correcto de la voz. A su vez, el conferenciante resaltó el papel que juegan los medios digitales como espacio de socialización, donde también tiene su lugar la conversación trivial del día a día y la preocupación por el otro. Además de las propuestas recreativas referidas anteriormente, una actividad que da cuenta de la postura afín a la interactividad es el "Salón de Lectura y Meditación", un espacio de intercambio informal "en el que serás protagonista", según remarca la convocatoria. La consigna de esta actividad reza: "seguramente hubo algo que leíste del Maestro que te impactó o que abrió algo dentro tuyo: iLeelo y Compartilo! Debe ser algo breve, de uno o dos párrafos, que leerás para todos, y luego tomaremos unos minutos para meditar en esas palabras ("Grupo de práctica Tashigar Sur 2020", Facebook). También da cuenta de un alto grado de interactividad el hecho de que los encargados de las actividades online son los propios integrantes del grupo, es decir, los más de ochenta instructores y practicantes destacados de $d z o g c h e n$ que trasmitieron la gran variedad de charlas y prácticas detalladas previamente.

Finalmente, hay que remarcar que los tres casos estudiados aquí representan las secciones locales de organizaciones budistas internacionales que aglutinan miembros y centros de práctica espacialmente alejados, conformando comunidades religiosas dispersas y fragmentadas. En este contexto, las nuevas tecnologías contribuyen a la formación de comunidades transnacionales pues reemplazan con interacciones a distancia, ya sean textuales o audiovisuales, las interacciones 
sociales presenciales. Por ello un aspecto importante de la mediatización observada durante la cuarentena en los casos estudiados es el que se refiere a la producción de identidades colectivas que trascienden territorios y barreras nacionales. Por ejemplo, dos meses después de la cuarentena, el grupo zen de la ciudad de La Plata organizó un encuentro de meditación que reunió a toda la comunidad de Latinoamérica y de Europa. Si bien fue llamada "Sesshin ${ }^{22}$ de La Plata", este centro local estaba en realidad cerrado y cada meditación fue "dirigida" por distintos maestros y maestras residentes en otras ciudades o países: Stephane Kosen Thibaut (Francia), Pierre Soko Lerouz (Chile), Toshiro Taigen Yamahuchi (Buenos Aires, Argentina) y Ariadna Dosei Labbate (Córdoba, Argentina) y Paula Reikuku Femenias (Suecia). La convocatoria señalaba:

En este período particular, esta sesshin será dirigida conjuntamente por Maestras y Maestros de la Kosen Sangha de Latinoamérica y Europa. Este evento es una oportunidad única para reunir a toda la Sangha y practicar juntos. Te invitamos a hacer todos los zazenes, de la misma manera en que practicamos durante una sesshin. Conscientes de que todas y todos estamos "en casa", con lo que esto implica, cada una y cada uno hará lo que mejor pueda.

(Dojo Zen Virtual Kosen Sangha, Facebook, 2020).

A partir de esta experiencia inicial se realizaron otras jornadas y sesshines bajo la misma modalidad que combina lo local y lo global. Además, se compartieron de forma online con el resto del mundo algunas de las prácticas de zazen que se estaban realizando de forma presencial en el templo de Europa 2020. En este contexto, una práctica habitual resultó ser la publicación en Facebook de fotos de las personas que participaron de un evento online: "como veis en estas fotos, nos estamos conectando a diario desde muchos puntos del planeta, para hacer zazen entre todos" (Dojo Zen Virtual Kosen Sangha, Facebook, 2020) reza la leyenda que las acompaña. De manera comparable, en el caso de la Asociación Vipassana, hubo invitaciones ocasionales a compartir meditaciones grupales organizadas por centros de Chile y EEUU al inicio de la cuarentena. Posteriormente, se estableció una "Meditación Grupal Vipassana en Latinoamérica" todos los domingos a las 10.00 hs., que reúne a todos los meditadores de esta región. Y en el caso del dzogchen, la dinámica global/local del proceso de mediatización puede observarse casi cotidianamente pues, como mencionamos, las trasmisiones son realizadas por una gran variedad de practicantes que residen en casi veinte países diferentes. Al respecto, uno de los miembros del grupo señalaba que "practicar vía Internet es casi como viajar... nos encontramos de todo el mundo en

22 El término japonés "sesshin" se refiere a un periodo de práctica intensiva de meditación zen que se extiende a lo largo de varios días. 
cada sesión de práctica... iEs como un mini Dzamlingar ${ }^{23}$ Zoom land!" ("Grupo de práctica Tashigar Sur 2020", Facebook).

\section{Reflexiones finales}

La indagación aquí presentada testimonia la transformación del budismo debido a su desplazamiento al ámbito de internet, conformando espacios de práctica alejados de los tradicionales donde lo sagrado se reelabora y se experimenta a través de flujos comunicacionales que circulan por redes digitales. La mediatización de las actividades budistas en el marco de la pandemia del Covid-19 se ha realizado mediante un proceso abrupto, intencional, reflexivo y planificado. La participación en las actividades virtuales antes de la pandemia era pensada en términos complementarios al mundo offline, priorizando siempre la presencialidad. Por el contrario, durante la crisis del Covid-19 la búsqueda por brindar un espacio de encuentro que posibilitara continuar con la práctica y mantener el contacto con el resto de los practicantes produjo una aceleración y complejización del paisaje mediático, el cual se tornó central y alcanzó un protagonismo impensado. En este proceso, los tres grupos estudiados contaron con la ventaja de tener un acervo de recursos previos en el manejo de los medios digitales, lo cual probablemente contribuyó a la rápida adaptación a la situación.

En pocos días, agentes clave tomaron medidas de emergencia para dar continuidad a las prácticas que se realizaban de forma presencial por medios digitales. Fue un proceso creativo de ensayo y error donde se recrearon rituales online y se enseñaron a usar herramientas como Zoom y Facebook Live, buscando equilibrar las desigualdades en el acceso al mundo digital-determinadas por los diferentes grados de experticia de los agentes individuales- mediante una labor pedagógica institucional. Esto brinda un claro ejemplo de lo que Campbell (2005) denomina "spiritualizing the internet", fenómeno por el cual se concibe esta tecnología como algo apropiado para la vivencia de la dimensión religiosa, alentando a los miembros del grupo a incluir actividades cotidianas online en su vida espiritual. Aquí es preciso destacar la creatividad y la agencia por la cual los diversos actores sociales crearon un nuevo espacio en el ambiente digital, testimoniada por actividades como las conferencias sobre diversos tópicos organizadas por el grupo tibetano y la terminología para designar las nuevas prácticas del grupo zen, tales como "za-zoom" y "shiat-zoom". Asimismo, cabe señalar que establecer un espacio virtual es establecer un nuevo espacio de sociabilidad, como lo demuestran las actividades informales y recreativas tales como el yoga, los masajes y las clases de cocina realizadas en un ámbito distendido donde la interactividad ocupan un lugar central.

Por otra parte, la alta frecuencia de actividades diarias online que se estableció durante la pandemia presenta una cadencia que, más que reproducir lo que

23 Se refiere al centro (gar) de todas las actividades y la administración de la Comunidad Dzogchen Internacional en todo el mundo, ubicado en la Isla de Tenerife, España. 
sucedía previamente en el mundo offline, se revela con una intensidad superadora de la habitual. En otras palabras, ni en los grupos zen, ni tibetano ni vipassana se convocaba a actividades presenciales $-\mathrm{O}$ virtuales - de forma tan frecuente, variada y gratuita como antes de la crisis sanitaria. Probablemente, una de las causas de esta hiper-mediatización sea la disponibilidad de un público que, durante el aislamiento impuesto por la cuarentena, buscó respuestas, guía y un sentido espiritual a los inquietantes acontecimientos que está atravesando. En este sentido, las actividades online proporcionaron un marco de contención ante la pandemia del Covid-19 y el aislamiento social que generó para combatirla, que incluyó una comunidad de personas con intereses semejantes con la cual interactuar, un sistema de significaciones acerca de la vida y la muerte, una conceptualización de la naturaleza de la enfermedad y los mecanismos para combatirla y un cronograma diario de actividades que en ocasiones pudo resultar de ayuda contra la anomia y el desconcierto producido por la interrupción de las rutinas cotidianas. Este factor de contención emocional también se revela en el hecho mencionado previamente de que los grupos estudiados fomentaron una actitud tranquilizadora hacia la pandemia y refractaria al alarmismo infundido por los medios de comunicación.

Si bien la práctica de la religión en el ambiente digital implica una transformación de la experiencia de lo sagrado "dada por medio de nuevas temporalidades, nuevas espacialidades, nuevas materialidades, nuevas discursividades y nuevas ritualidades" (Sbardelotto 2014:12), tras el recorrido efectuado podemos afirmar que las dinámicas sociales referentes a cuestiones de accesibilidad, interactividad y sociabilidad a menudo reprodujeron la lógica offline. El grupo vipassana mantuvo la reserva y la sobriedad que lo caracteriza y, limitado prácticamente a los que tuvieron la vivencia de primera mano en los cursos de diez días -verdadera experiencia iniciática que opera como barrera indiscutible para limitar las fronteras de la comunidad-, se centró en fomentar la práctica diaria de la meditación sin propiciar la interactividad. El grupo zen también continuó con el énfasis en la meditación, pero a su propia manera, donde lo importante es meditar "con el maestro", "todos juntos", "con una buena postura”. El medio digital se adaptó para satisfacer la lógica presencial donde cada cual tiene su lugar en el dojo, donde hay que vestirse con ropas ceremoniales y la cabeza afeitada, donde todos miran y son mirados y es importante "estar ahî" día tras día testimoniando el férreo espíritu de determinación zen, y donde el maestro corrige las posturas físicas de la meditación con un apasionamiento casi moral. Y, por su parte, el grupo de budismo tibetano continuó haciendo gala de su habitual polifonía y eclecticismo, dando lugar a una multiplicidad de prácticas que se recrean continuamente, que van desde tecnologías del yo como el yoga, la meditación y la danza, hasta actividades informales surgidas de la iniciativa de sus propios miembros como las clases de ikebana y el espacio de lectura.

En todo caso, el fenómeno de hiper-mediatización examinado aquí brinda testimonio del poder de las nuevas tecnologías digitales a la hora de construir un 
sentido de pertenencia que trasciende fronteras geográficas. Aunque cada uno esté en su hogar, el ciberespacio posibilita la construcción de una "comunidad de práctica" (Strauss 2000) transnacional, proporcionando un sentido de identidad colectiva basado en la idea de pertenecer a un grupo de gente que se encuentra "practicando junta". La intensa actividad audiovisual online y su registro crean las condiciones de posibilidad para que comunidades trasnacionales y globalizadas, construidas en base a afinidades religiosas como las estudiadas en este trabajo creen una identidad colectiva que trasciende fronteras locales. Y aquí vale mencionar que el acto de archivar que implica la grabación de las actividades realizadas online por parte del grupo zen y el tibetano puede pensarse, parafraseando a Appadurai (2005:127), como una creación "ex profeso para la producción de memorias anticipadas por comunidades intencionales". Toda esta documentación -fotos, textos y videos- es un proyecto colectivo, vinculado más con una aspiración que con un recuerdo: la aspiración de visibilizar una comunidad transnacional que testimonia su continuidad pesa al impacto de la crisis sanitaria global.

Con seguridad, la aceleración y complejización del paisaje mediático ha tenido como consecuencia incrementar la conciencia de esta identidad colectiva transnacional de las comunidades budistas estudiadas. A su vez, como afirma Robertson (1994), es preciso tener en cuenta que las identidades locales son parte intrínseca del proceso global contemporáneo, no como oposición a este proceso sino como forma de estar dentro del sistema global. En este sentido, los paisajes mediáticos globalizados "trastocan el sentido de lo local" (Appadurai 2001:188), ya que un evento ritual previamente limitado a una ciudad, debido a su traslado al medio digital incluye la participación de personas a una escala trasnacional. En el referido caso de la jornada de práctica del zen realizada en la ciudad de La Plata, que conserva ese nombre, aunque es dirigida por maestros de todo el mundo, podemos apreciar cómo los paisajes mediáticos contribuyen a una "producción global de lo local" (Appadurai 2001:196).

Para finalizar, resta mencionar que el recorrido realizado en este escrito abre el juego para diversas líneas de análisis posibles de ser abordadas en el futuro. Cuatro temáticas en particular destacan por su importancia a la hora de comprender las trasformaciones de la experiencia del budismo online generadas por la pandemia del coronavirus. En primer lugar, las conceptualizaciones nativas y los sentidos asociados a esta crisis sanitaria y la forma por la cual este fenómeno se inserta en las matrices simbólicas de cada grupo. En segundo lugar, el impacto de la religiosidad online en el proceso de producción de subjetividades, especialmente en la dimensión de la identidad y la corporalidad. En tercer lugar, los tratamientos rituales que se pusieron en juego para afrontar la enfermedad del Covid-19, las prácticas asociadas a su prevención o curación y su relación con el modelo medico hegemónico. Y, por último, el estudio del devenir de las nuevas prácticas virtuales en un futuro escenario post-pandémico, a fin de determinar el grado en el cual permanecieron tras el regreso 
a la llamada "nueva normalidad" y la manera en que se integraron a la interacción presencial.

\section{Referencias Bibliográficas}

ANDERSON, Benedict. (1983), Comunidades Imaginadas: Reflexiones sobre el origen y la difusión del nacionalismo. México: Fondo de Cultura Económica.

APPADURAI, Arjun. (2001), La modernidad desbordada. Dimensiones culturales de la globalización. Buenos Aires: Ediciones Trilce, FCE.

APPADURAI, Arjun. (2005), "Memoria, Archivo y Aspiraciones". In: Construir Bicentenarios: Argentina. Buenos Aires: The New School.

BAUMANN, Martin. (2001), "Global Buddhism: Developmental Periods, Regional Histories, and a New Analytical Perspective". Journal of Global Buddhism, n. 2: 1-43.

BAUMANN, Martin. (2002), "Protective Amulets and Awareness Techniques, or How to Make Sense of Buddhism in the West". In: PREBISH, Charles S. and Martin BAUMANN. Westward Dharma: Buddhism Beyond Asia. California: University of California Press.

BITARELlO, Maria Beatrice. (2008), "Another Time, Another Space: Virtual Worlds, Miths and Imagination". Heidelberg Journal of Religions on the Internet, vol. 3, $\mathrm{n}^{\circ}$ 1: 246-266.

CAMPBELL, Heidi. (2005), "Spiritualising the Internet: Uncovering Discourses and Narratives of Religious Internet Usage". Heidelberg Journal of Religions on the Internet, vol. 1, n 1: 1-26.

CAMPBELL, Heidi \& CONNELLY, Louise. (2012), "Cyber Behavior and Religious Practice on the Internet". In: ZHENG, Yan (ed.) Encyclopedia of Cyber Behavior, chapter 37: 434-446.

CARINI, Catón Eduardo. (2009), "La ceremonia de ordenación zen: etnografía de un rito de paso en el budismo argentino”. Ciencias Sociales y Religión/Ciências Sociais e Religião, año 11, n 11: 157-180.

CARINI, Catón Eduardo. (2010), "Don ritual y trabajo sagrado: la ética económica de los centros budistas zen de la Argentina". Revista de Ciencias Sociales, vol. 24: 7-26.

CARINI, Catón Eduardo. (2012), Etnografía del Budismo Argentino: rituales, cosmovisión e identidad. La Plata: Tesis Doctoral en Antropología, Universidad Nacional de La Plata.

CARINI, Catón Eduardo. (2016), "Budas en movimiento: la práctica de la danza y el yoga tibetano en una comunidad vajrayana argentina". Religare, vol. 13, n 2: 321-347.

CARINI, Catón Eduardo. (2017), "Flujos y reflujos en el desarrollo del budismo asiático: un recorrido por la historia del movimiento de meditación vipassana". NUMEN - Revista de Estudos e Pesquisa da Religião, vol. 20, n 1: 7-27.

CARINI, Catón Eduardo. (2019a), "El budismo tibetano en el ciberespacio: nuevas tecnologías de la información y comunicación en la Comunidad Dzogchen Internacional”. PAAKAT: Revista de Tecnología y Sociedad, año 9, n 17: 1-15.

CARINI, Catón Eduardo. (2019b), "Etnicidad, utopía y globalización en la reinvención del budismo tibetano. El caso de la Comunidad Dzogchen Internacional”. Sociedad y Religión, vol. 29, n 51: 168194.

CARINI, Catón Eduardo \& GRACIA, Agustina. (2016), "Ritual, identidad y transnacionalización en una celebración budista: el Vesak en la Argentina”. RUNA - Archivo para las ciencias del hombre, vol. $37, n^{\circ} 1: 5-20$.

CASEY, Cheryl. (2006), "Virtual Ritual, Real Faith: The Revirtualization of Religious Ritual in Cyberspace". Heidelberg Journal of Religions on the Internet, vol. 2, $\mathrm{n}^{\circ}$ 1: 73-90.

CONNELLY, Louise. (2010), "Virtual Buddhism: An Analysis of Aesthetics in Relation to Religious Practice within Second Life". Heidelberg Journal of Religions on the Internet, vol. 4, $n^{\circ}$ 1: 12-34.

FOUCAULT, Michel. (1990), Tecnologías del yo y otros textos afines. Barcelona: Paidos. 
GRACIA, Agustina. (2019), "Energías en línea: una exploración de los modos de sociabilidad virtual en el caso de la 'Llave Mariana”. PAAKAT. Revista de Tecnología y Sociedad, vol. 9: 1-17.

GRIEVE, Gregory Price. (2010), "Virtually Embodying the Field: Silent Online Buddhist Meditation, Immersion, and the Cardean Ethnographic Method". Heidelberg Journal of Religions on the Internet, vol. $4, \mathrm{n}^{\circ} 1: 35-62$.

HELLAND, Christopher. (2005), "Online Religion as Lived religion. Methodological Issues in the Study of Religious Participation on the Internet". Heidelberg Journal of Religions on the Internet, vol. $1, \mathrm{n}^{\circ} 1$ : 28-54.

KRUGER, Oliver. (2005), "Discovering the Invisible Internet: Methodological Aspects of Searching Religion on the Internet". Heidelberg Journal of Religions on the Internet, vol. 1, $n^{\circ}$ 1: 1-27.

MACWILLIAMS, Mark. (2006), "Techno-ritualization: The gohonzon controversy on the internet". Heidelberg Journal of Religions on the Internet, vol. 2, $\mathrm{n}^{\circ}$ 1: 54-72.

PORTES, Alejandro. (2003), "Conclusión: Hacia un nuevo mundo. Los orígenes y efectos de las actividades transnacionales”. In: A. PORTES, L. GUARNIZO \& P. LANDOLT (Coords.). La Globalización desde abajo: transnacionalismo inmigrante y desarrollo. La experiencia de Estados Unidos y América Latina. México, FLACSO/Porrúa: 377-394.

RADDE-ANTWEILER, Kerstin. (2006), "Rituals Online. Transferring and Designing Rituals". Heidelberg Journal of Religions on the Internet, vol. 2, $\mathrm{n}^{\circ}$ 1: 54-72.

RADDE-ANTWEILER, Kerstin. (2008), "Virtual Religion'. An Approach to a Religious and Ritual Topography of Second Life". Heidelberg Journal of Religions on the Internet, vol. 3, n ${ }^{\circ}$ 1: 174-211.

ROBERTSON, Roland. (1994), "Religion and the global field". Social Compass, vol. 41, n¹: 121-135.

SBARDELOTTO, Moisés. (2014), "La reconstrucción de lo "religioso" en la circulación en redes sociodigitales”. La Trama de la Comunicación, vol. 18: 151-170.

SOPER, Catherine Elizabeth. (2014), Constructing a Buddhist-Inspired Framework for Examining Tulkus' use of Cyberspace. Wellington: Tesis de maestría, Victoria University of Wellington.

STRAUSS, Sara. (2000), "Locating yoga. Ethnography and transnational practice". In: AMIT, Vered (ed.) Constructing the Field: Ethnographic Fieldwork in the Contemporary World. London and New York: Routledge, 2000: 46-62.

TAROCCO, Francesca. (2017), "Technologies of Salvation: (Re)locating Chinese Buddhism in the Digital Age". Journal of Global Buddhism, vol. 18: 155-175.

VERTOVEC, Steven. (2003), “Concebir e investigar el transnacionalismo". In: A. PORTES, L. GUARNIZO y P. LANDOLT (Coords.). La Globalización desde abajo: transnacionalismo inmigrante y desarrollo. La experiencia de Estados Unidos y América Latina. México, FLACSO/Porrúa: 353-376.

YONNETTI, Eben. (2017), "Tibetan Buddhism in the Digital Age: Exploring Online Buddhist Study, Practice, and Community on Ocean: The Vast Teachings of Chögyam Trungpa". NEXT: vol. 5, $\mathrm{n}^{\circ}$ 6: $1-21$.

\section{Sitios web consultados}

"Vipassana Argentina - Estudiantes Antiguos (Oficial)", Facebook. Consultado el: 25/08/2020.

"Dojo Zen Virtual Kosen Sangha”, Facebook. Consultado el: 18/08/2020.

“Grupo de práctica Tashigar Sur 2020”, Facebook. Consultado el: 29/08/2020.

Submetido em: 30/11/2020

Aprovado em: 19/08/2021 


\section{Catón Eduardo Carini* (catoncarini@yahoo.com.ar)}

* Investigador adjunto del Consejo Nacional de Investigaciones Científicas y Técnicas (CONICET), Sección Etnología del Instituto de Ciencias Antropológicas, Universidad de Buenos Aires, Buenos Aires, Argentina; docente de la Facultad de Psicología, Universidad Nacional de La Plata (UNLP); Doctor en Antropología por la Facultad de Ciencias Naturales, UNLP. 


\section{Resumen:}

\section{La práctica online del budismo en tiempos de pandemia: rituales, comuni- dad y mediatización}

Desde fines del año 2019 la población mundial se ha visto convulsionada por la irrupción de un virus previamente desconocido que se esparce rápidamente y cobra miles de víctimas fatales cada día. Muchos países del globo han cerrado sus fronteras y decretado la cuarentena o aislamiento social preventivo, trastocando la vida cotidiana de la comunidad internacional de una forma nunca antes vista. En este contexto, se ha visto incrementado el uso de las nuevas tecnologías digitales de comunicación a distancia como forma de continuar con actividades hasta hace poco realizadas presencialmente, tales como el trabajo, el estudio, las relaciones sociales y la práctica de la religión. En este trabajo exploramos las mudanzas observadas en el empleo de internet en el marco de grupos budistas de la Argentina debido a la crisis generada por el Covid-19, indagando especialmente en la creación de nuevos rituales online y la construcción de un sentimiento de comunidad que atraviesa las fronteras locales, nacionales y globales.

Palabras clave: budismo; internet; Covid-19; ritual

\section{Resumo:}

\section{A prática online do budismo em tempos de pandemia: rituais, comunidade e midiatização}

Desde o final de 2019, a população mundial foi convulsionada pela irrupção de um vírus até então desconhecido que se espalha rapidamente e causa milhares de mortes todos os dias. Muitos países ao redor do mundo fecharam suas fronteiras e decretaram quarentena ou isolamento social preventivo, perturbando a vida diária da comunidade internacional de uma forma nunca vista antes. Nesse contexto, tem se intensificado o uso de novas tecnologias de comunicação digital a distância como forma de dar continuidade a atividades que eram realizadas presencialmente até recentemente, como o trabalho, o estudo, as relações sociais e a prática da religião. Neste trabalho exploramos as mudanças observadas no uso da internet no âmbito dos grupos budistas na Argentina devido à crise gerada pela Covid-19, investigando especialmente a criação de novos rituais online e a construção de um sentido de comunidade que atravessa as fronteiras locais, nacionais e globais.

Palavras-chave: budismo; Internet; Covid-19; ritual 


\section{Abstract:}

\section{The online practice of Buddhism in times of pandemic: rituals, community and mediatization}

Since the end of 2019, the world population has been convulsed by the irruption of a previously unknown virus that spreads rapidly and claims thousands of fatalities every day. Many countries around the globe have closed their borders and decreed quarantine or preventive social isolation, disrupting the daily life of the international community in a way never seen before. In this context, the use of new information and communications technology has increased as a way of continuing with activities that were carried out in person until recently, such as work, study, social relations and the practice of religion. In this work we explore the changes observed in the use of the internet in the framework of Buddhist groups in Argentina due to the crisis generated by Covid-19, especially investigating the creation of new online rituals and the construction of a sense of community that it crosses local, national and global borders.

Keywords: Buddhism; internet; Covid-19; ritual 